\title{
FAST AND RELIABLE METHOD FOR MONITORING EPOXIDATION REACTION IN RECYCLED VEGETABLE OILS (ERVO) USING FTIR-ATR TECHNIQUE
}

\author{
CHRISTIAN NÚNEEZ*1,3 EMILIO VERGARA ${ }^{1,2}$ JUSTO LISPERGUER ${ }^{1,2}$, CYNTHIA DROGUETT $^{1,4}$ \\ ${ }^{1}$ Universidad del Bio-Bio, Facultad de Ciencias, Departamento de Química, Av. Collao 1202 Concepción, Chile. \\ ${ }^{2}$ Centro de Investigación de Polímeros Avanzados, CIPA, Beltrán Mathieu 224, piso 2, Concepción, Chile \\ ${ }^{3}$ Centro de Biomateriales y Nanotecnología (CBN), Av. Collao, 1202 Concepción, Chile. \\ ${ }^{4}$ Laboratorio de Materiales Compuestos (LMC), Av. Collao, 1202 Concepción, Chile. \\ Highlights \\ - High yields were obtained when using $\mathrm{H}_{2} \mathrm{O}_{2}$ /Formic Acid for epoxidizing recycled vegetable fatty acids. \\ - The iodine value of the fatty acid indicates the highest degree of epoxidation at the end of the process. \\ - It is possible to correlate the progress of epoxidation from infrared studies. \\ - Coefficient of determination $\left(\mathrm{r}^{2}\right)$ up to 0.995 was obtained by comparing the two methodologies for monitoring the epoxidation.
}

\section{INTRODUCTION}

Recycled oils had been a viable alternative for the generation of biodiesel and higher value-added derivatives. Among these derivatives are also bioplasticizers for polymers. Vegetable oils provide a sustainable alternative for plasticizers manufacture, due to the presence of their unsaturation a chemical modification by an epoxidation reaction is possible. Moreover, the use of recycled oils for bioplastificizers preparation is cheaper and profitable ${ }^{1}$. However since it is a complex mixture of vegetable oils, prior characterization of the fatty acids variety making up the mixture to generate bioplasticizer is necessary ${ }^{2}$. Costs associated with monitoring of these kinds of reactions are usually high ${ }^{3}$.

Worldwide, the replacement of oil by renewable raw materials is faced with comprehensive policies for developing an economy based on three pillars: energy production, biofuels and production of chemicals different to food use, also the issue of recycling waste has become a critical problem ${ }^{4}$. In Chile, there are initiatives like using recycled biodiesel to generate electricity in remote communities and the Ministry of Energy has encouraged these types of activities $^{5}$. Currently the raw materials for the chemical industry are fossil; oil, natural gas and others; only a small amount is renewable, among these products are biodiesel and bioplasticizers for plastics such as $\mathrm{PVC}^{6}$. Historically, epoxides have been obtained from petroleum, however they have important drawbacks in terms of environmental, health and energy consumption ${ }^{7}$.

The most common methods for preparing epoxides from vegetable oils is the use of peracids ${ }^{8,9}$, oxidation with molecular oxygen using catalytic methods (acidic zeolites) $)^{10}$, enzymatic methods utilizing lipases ${ }^{11}$.

In situ FTIR-ATR analysis has become a powerful analytical tool in the study of edible oils and fats. It's fast, non-destructive and requires minimal preparation. Furthermore, the FT-IR spectroscopy is an excellent tool for quantitative analysis. Intensities of the bands of the spectrum are proportional to the concentration of the sample (Beer's law is satisfied). Infrared spectra in the middle range is used to characterize the edible fats and oils, because they differ in the intensity and exact frequency at which the maximum absorbance appears, according to the nature and composition of the sample ${ }^{12,13}$. Using the relationships between the absorbance values eliminates all possible variables involved in sample preparing, spectrum acquisition and sample thickness.

Oils epoxidation monitoring are possible using equations like:

$$
x=\left[1-\frac{\left(A_{806} / A_{1376}\right)_{t}}{\left(A_{806} / A_{1376}\right)_{0}}\right] \times 100
$$

Wherein $\mathrm{A}_{806}$ and $\mathrm{A}_{1376}$, are areas under the curve of the absorption bands at $806 \mathrm{~cm}^{-1}$; characteristic of $\mathrm{C}=\mathrm{C}$ double bond; and $1376 \mathrm{~cm}^{-1}$ corresponds to methyl ester, subscripts 0 and $t$ indicate values at the start of the reaction and at time $t$. As the latter band kept constant serves as internal. The method is very fast because it is sufficient to read in the FTIR data and apply in equation $(1)^{14}$.

It is known that during the epoxidation process of the double bonds wherein a slight decomposition of methyl ester is generated and also the above equation is also satisfied in the presence of pure fatty acids ${ }^{15}$. The goal of this research is to find a fast and reliable method for monitoring the epoxidation reaction of recycled vegetable oils methyl esters (EAVR) of a complex mixture of fatty acids using FTIR-ATR technique. This paper proposes a fast and reliable method using FTIR spectroscopy to monitor epoxidation reaction thereby avoiding waste of time and resources. This reduces production costs, is environmentally friendly and reduces chemical residues.

\section{MATERIALS AND METHODS}

\subsection{Materials}

Methyl ester from fatty acids recovered from vegetable frying oils at Santiago (FAME Ltda. Santiago, Chile), $50 \% \mathrm{H}_{2} \mathrm{O}_{2}$ (Merck), $88 \%$ formic acid (Merck), $\mathrm{NaCl}$ (Merck), $\mathrm{Na}_{2} \mathrm{CO}_{3}$ pa (Merck), anhydrous Na2SO4 (Winkler Ltda.), Boron trifluoride (Aldrich).

2.2 Characterization of the complex mixture from recycled vegetable oil (RVO)

The complex mixture of methyl esters from recycled vegetable oils was characterized using gas chromatography with an FID detector, using a Supelco SPB-PUFA column of $30 \mathrm{~m} \times 0.25 \mathrm{~mm} \times 0.2 \mu \mathrm{m}$ film. To obtain the corresponding methyl esters, the samples were pre-treated with boron trifluoride. Determination of iodine and oxirane values was carried out according to NTC $2366^{16}$ and acidity according to NTC $3305^{17}$.

2.3 Experimental Procedure for the preparation of (EAVR)

To determine the optimal conditions of epoxidation process, two working temperatures 50 and $60^{\circ} \mathrm{C}$ were chosen for three different molar ratios of $\mathrm{H}_{2} \mathrm{O}_{2}$ $(1.1,2$ and 4$)$ and two different molar ratios of formic acid ( 0.5 to 1$)$ regarding the mixture of methyl esters.

Epoxidation was conducted in a three-necked flask under reflux in thermostated water bath (Buchi B-430), which was stirred with a propeller (IKA RW 20) at $400 \mathrm{rpm}$. The mixture of methyl esters, and also formic acid was added to the flask. Then hydrogen peroxide was added slowly to prevent an increase in temperature. The temperature was regulated with a thermostatic bath. The reaction time was three hours, during which the samples were collected for analysis using conventional analysis techniques like oxiranes and FTIR-ATR measurements. The sampling times were $0,10,20,30,60,90,120$ 150 and 180 minutes. Each sample taken was mixed with $1 \% \mathrm{NaCl}$ and washed with a solution of $4 \% \mathrm{NaHCO}$ to neutralize the $\mathrm{pH}$. The samples are dried with anhydrous $\mathrm{Na} 2 \mathrm{SO} 4$ and were determines the oxirane index and evaluated by FTIR-ATR measurements. The IR spectroscopy equipment used was Perkin Elmer UATR Two, with an adapter diamond ATR crystal.

2.4 Analytical techniques used for monitoring the epoxidation of RVO

Monitoring the reaction was carried out using the conventional analysis techniques: iodine and oxiranes (NTC 2366 ${ }^{16}$ ), and acid number (NTC $3305^{17}$ ). It was necessary to propose a new fast and reliable method for monitoring the epoxidation reaction to this new complex matrix of recycled fatty acids. Due to the multiple fatty acid presence, it was necessary to seek a new equation (2) using the $1742 \mathrm{~cm}^{-1}$ band as internal standard characteristic of an axial deformation for the $\mathrm{C}=\mathrm{O}$ group of aliphatic esters and the signal at $824 \mathrm{~cm}^{-1}$ identifying the oxirane ring, to monitor the course of epoxidation. 


$$
X=\left[1-\frac{\left(A_{806} / A_{1376}\right)_{1}}{\left(A_{806} / A_{1376}\right)_{0}}\right] \times 100
$$

\section{RESULTS AND DISCUSSION}

The fatty acid composition of the complex mixture of RVO, recycled vegetable oils, is presented in Table 1. High content of unsaturation in the fatty acids, oleic and linoleic, allows to the preparation of the corresponding oxiranes. Reported percentages are the relative areas obtained by gas chromatography with FID detector. Also it is necessary to characterize the iodine number to define the proportions of acid and hydrogen peroxide necessary for epoxidations.

Table1: Characterization of the complex mixture of vegetable fatty acids recycled AVR

\begin{tabular}{|l|c|c|}
\hline \multicolumn{1}{|c|}{ Compound } & $\begin{array}{c}\mathbf{N}^{\circ} \text { of carbons and double } \\
\text { bond }\end{array}$ & $\begin{array}{c}\text { Fatty acid content } \\
\text { (\%) }\end{array}$ \\
\hline Myristic acid & $\mathrm{C} 14: 0$ & 0.1 \\
\hline Palmitic acid & $\mathrm{C} 16: 0$ & 10.5 \\
\hline Stearic acid & $\mathrm{C} 18: 0$ & 3.1 \\
\hline Oleic acid & $\mathrm{C} 18: 1$ & 29.3 \\
\hline Linoleic acid & $\mathrm{C} 18: 2$ & 53.8 \\
\hline Linolenic acid & $\mathrm{C} 18: 3$ & 2.1 \\
\hline Arachidic acid & $\mathrm{C} 22: 0$ & 0.7 \\
\hline
\end{tabular}

The epoxidation process is carried out at two temperatures, 50 and $60^{\circ} \mathrm{C}$, three molar ratios for $\mathrm{H}_{2} \mathrm{O}_{2}(1.1,2$ and 4$)$ and two molar ratios for formic acid $(0.5$ to 1). The amounts were calculated relative to the index of unsaturation of the mixture of methyl esters. Epoxidation tracking was done for different time lengths $(0,10,20,30,60,90,120,150$ and 180 minutes). The iodine and oxirane values are shown in the following tables (table $2 \& 3$, respectively) at the end time of 180 minutes following traditional analysis techniques.

Table 2: Iodine index for reaction time 180 minutes.

\begin{tabular}{|c|c|c|c|c|c|c|c|}
\hline & & \multicolumn{3}{|c|}{ Temperature $50^{\circ} \mathrm{C}$} & \multicolumn{3}{|c|}{ Temperature $60^{\circ} \mathrm{C}$} \\
\hline & & \multicolumn{3}{|c|}{ Molar Ratio $\mathrm{H}_{2} \mathrm{O}_{2}$} & \multicolumn{3}{|c|}{ Molar Ratio $\mathrm{H}_{2} \mathrm{O}_{2}$} \\
\hline & & 1.1 & 2 & 4 & 1.1 & 2 & 4 \\
\hline Molar Ratio & 0.5 & 1.64 & 1.54 & 1.10 & 19.36 & 5.45 & 2.20 \\
\hline Formic Acid & 1 & 6.71 & 2.17 & 3.22 & 1.52 & 3.20 & 4.48 \\
\hline
\end{tabular}

Table 3: Oxirane index for reaction time 180 minutes.

\begin{tabular}{|c|c|c|c|c|c|c|c|}
\hline & \multicolumn{3}{|c|}{ Temperature $50^{\circ} \mathrm{C}$} & \multicolumn{3}{|c|}{ Temperature $60^{\circ} \mathrm{C}$} \\
\hline & & \multicolumn{3}{|c|}{ Molar Ratio $\mathrm{H}_{2} \mathrm{O}_{2}$} & \multicolumn{3}{|c|}{ Molar Ratio $\mathrm{H}_{2} \mathrm{O}_{2}$} \\
\hline & & 1.1 & 2 & 4 & 1.1 & 2 & 4 \\
\hline Molar Ratio & 0.5 & 6.76 & 5.44 & 7.46 & 4.78 & 5.27 & 5.27 \\
\hline Formic Acid & 1 & 4.09 & 5.13 & 5.24 & 6.50 & 6.27 & 4.84 \\
\hline
\end{tabular}

\subsection{Effect of hydrogen peroxide in the formation of oxirane}

The effect of hydrogen peroxide on unsaturation for epoxide formation was studied at three different molar ratios $\mathrm{H}_{2} \mathrm{O}_{2}$ /ethylene unsaturation $(1.1,2$ and 4), it was observed that for a given temperature increase of $\mathrm{H}_{2} \mathrm{O}_{2}$ for 180 min, produces a significant reduction of iodine index and an increase in the rate of oxirane. Highest rate of oxirane conditions was observed for $\left(50{ }^{\circ} \mathrm{C}\right.$; molar ratio of 4 for $\mathrm{H}_{2} \mathrm{O}_{2}$; molar ratio of 0.5 for formic acid) conditions matching the lowest rate of iodine.

3.2 Formic Acid Effect on formation of oxirane

The formic acid was studied at two molar ratios ( 0.5 and 1$)$, observing the increase in the ratio of acid at $50^{\circ} \mathrm{C}$ produces a decrease in oxirane content, because the acid catalyzes the formation of oxirane and in larger amounts generates hydrolysis of the oxirane ring, thereby decreasing their content for $180 \mathrm{~min}$. However, at $60^{\circ} \mathrm{C}$ the opposite effect was observed, oxirane content increases, but for molar ratio of 4 for $\mathrm{H}_{2} \mathrm{O}_{2}$ increased acid concentration causes a decrease of the content of oxirane index.

3.3 Effect of temperature on the formation of oxirane

Temperature is another important factor in the formation of epoxide. Studies at 50 and $60^{\circ} \mathrm{C}$ for the same conditions for a ratio of 0.5 of formic acid shows a decrease in oxirane content which could be due to hydrolysis of oxirane ring at the temperature of $60^{\circ} \mathrm{C}$. However, for the molar ratio 1 of formic acid, oxirane content was found to increase with increasing temperature. When the molar ratio of $\mathrm{H}_{2} \mathrm{O}_{2}$ was 4 at $60^{\circ} \mathrm{C}$ the oxirane content was found to decrease for 180 minutes.

Optimum conditions for preparing the epoxide with lower energy costs and lower amounts of reagent for the conversion can be obtained for epoxidation studies on recycled vegetable oils (ERVO). Under these conditions the best working conditions were: at $50^{\circ} \mathrm{C}$ temperature; molar ratio 4 of $\mathrm{H}_{2} \mathrm{O}_{2}$; formic acid molar ratio of 0.5 , for 180 minutes. With the optimal conditions we can monitor the formation of epoxide using FTIR-ATR spectroscopy from equation (2).

4 Monitoring epoxidation reaction of recycled vegetable oils (ERVO) using FTIR-ATR technique

To quantify the epoxide generated and for monitoring the epoxidation reaction using FTIR-ATR spectroscopy, equation (2) was used. The signals used to monitor the reaction are shown in figure 1. Overlap of samples indicates the evolution of reaction with time of reaction. 

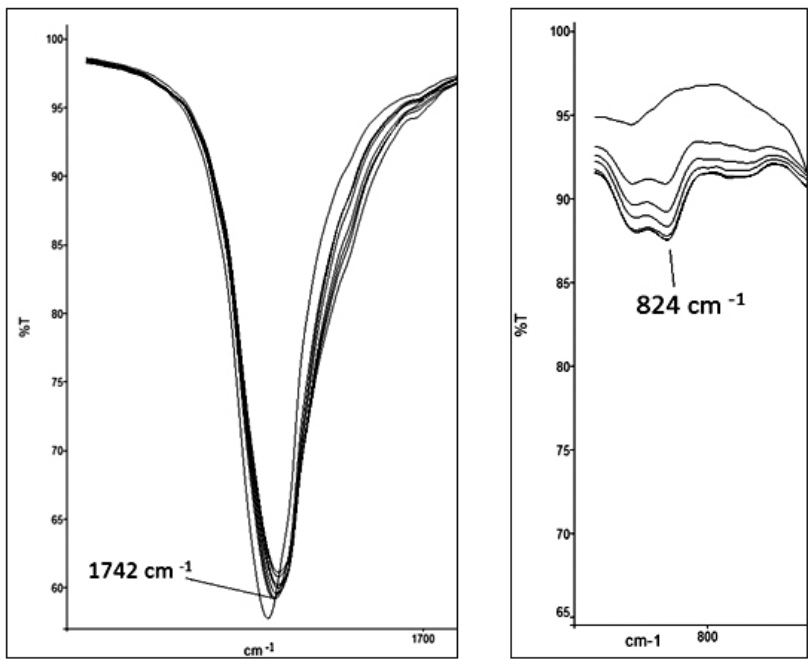

Figure 1: ATR-FTIR spectrum at different reaction times for monitoring and quantifying the formation of epoxide, a) enlargement of the $\mathrm{C}=\mathrm{O}$ signal as an internal reference, $b$ ) magnification of vibration corresponding to oxirane.

Oxirane content obtained from chemical analysis was the same obtained by using equation (2), with a coefficient of determination $\left(\mathrm{r}^{2}\right)$ equal to 0.995 (figure 2). In this way we can obtain reliable data for the quantification of oxirane using FTIR-ATR technique for complex mixtures.

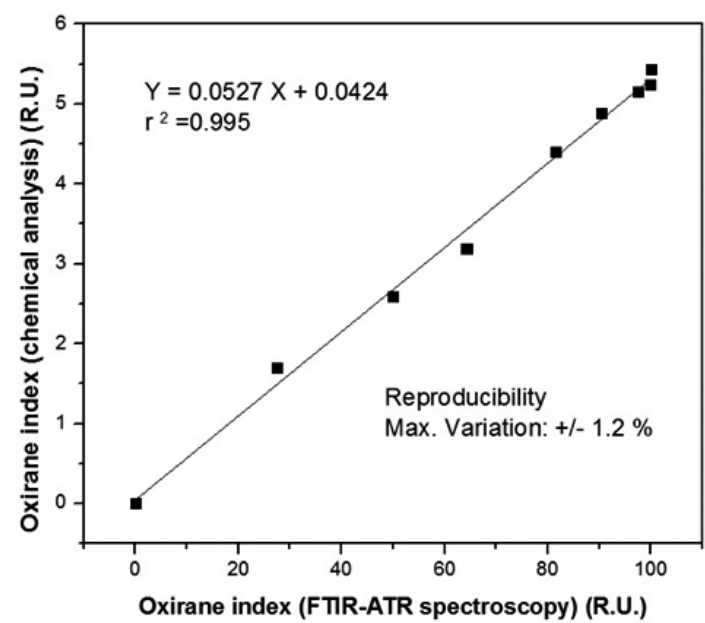

Figure 2: Oxirane content correlation obtained by chemical analysis $\mathrm{v} / \mathrm{s}$ oxirane content determined by FTIR-ATR spectroscopy.

Once validated, this method can be used to monitor the formation of oxirane directly. Figure 3 presents the oxirane v/s reaction time determined using FTIR-ATR spectroscopy.

\section{Epoxidation reaction on recycled vegetable oils (ERVO)}

A good correlation (Figure 2) between the chemical determination by titration according oxirane NTC 2366 and oxirane measuring using the FTIR-ATR spectroscopy was observed. Oxirane index of $7.46 \%$ with a $1.2 \%$ reproducibility using the FTIR-ATR technique was obtained. The obtained epoxides show oxirane content in agreement with the iodine index or double bonds number of the triglyceride oil. The iodine value of 121.6 was used which corresponds to $82 \%$ yield of ERVO, which according to the theoretical equation by Espinoza ${ }^{18}$, generates a product with $7.1 \%$ oxirane and equation by Boyaca and Beltrán corresponds to $7.7 \%{ }^{19}$. These authors, reported oxirane index between 4.3 and $7.2 \%$ obtained from separate studies, corresponding to yield ranging from $43-88 \%$ of the theoretical yield; only $80 \%$ was expected for epoxidation reactions in in-situ studies.

Espinoza $^{18}$ indicates that the iodine values for its 16 treatments were reduced from $93 \%$ to $99.7 \%$ relative to starting iodine in canola oil. Reductions in iodine values were interpreted as the consumption due to unsaturated during epoxidation, however one should consider the performance as a percentage of epoxy rings that can decompose generating byproducts.

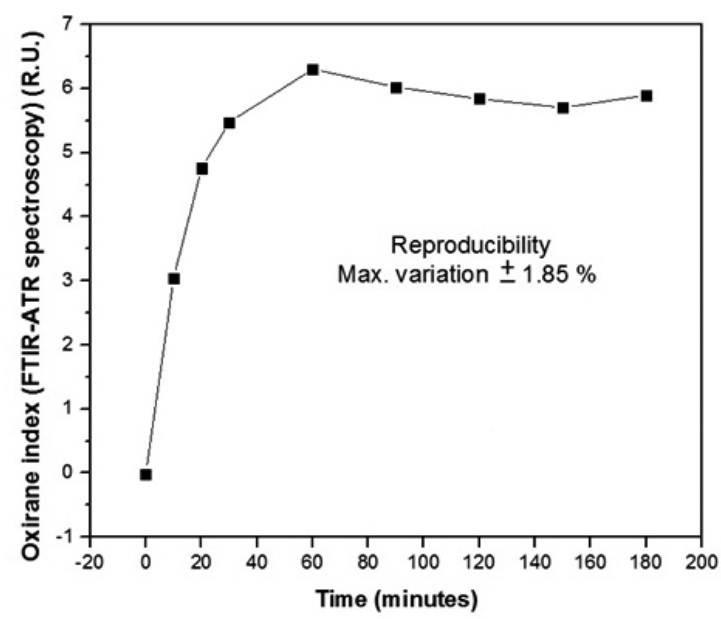

Figure 3: Representation of oxirane v/s time using FTIR-ATR.

\section{CONCLUSIONS}

This paper reports the conversion of ERVO industry frying to their corresponding epoxides. Characterization of this mixture indicated that there was a very high percentage of unsaturation. Best reaction conditions with low reagent consumption and energy were: for temperature $50^{\circ} \mathrm{C}$; Molar Ratio 4 of $\mathrm{H}_{2} \mathrm{O}_{2}$; Molar Ratio 0.5 of formic Acid, for 180 minutes. The epoxidation process was optimized using spectroscopic FTIR-ATR technique, achieving a good correlation between the data obtained by chemical analysis and IR spectroscopic technique. This indicates that the ATR-FTIR technique is a reliable tracking technique for epoxidation reaction. Transformation yields observed for epoxides with double bonds was $82 \%$. The product obtained had an oxirane content of $7.46 \%$, higher when compared with commercial products from other sources of vegetable fatty acids.

\section{ACKNOWLEDGEMENTS}

This work was funded by University of Bio-Bio under the research grant DIUBB 120306 3/R and DIUBB 140406 3/R. We are also grateful to the authorities of the University of Bio-Bio, Department of Chemistry, UBB, Faculty of Science for dissemination of this research at conferences and supporting for publications. In addition to the Center of Biomaterials and Nanotechnology (CBN), we also acknowledge CIPA, CONICYT Regional, GORE BIO BIO R08C1002 and Laboratory Adhesives and Composites (LMC).

\section{REFERENCES}

1. V. Goud, A. Patwardhan, S. Dinda, S. Pradhan. Eur. J. Lipid Sci. Tech. 109:575-584, (2007).

2. C. Nuñez, E. Vergara, W. Gacitúa, P. Valenzuela. XXX Jornadas Chilenas de Química. Libro Resumen. Pag. QM312. (2013).

3. S. Anuar, Y. Zhao, S. Mugo, J. Curtis. J. Am. Oil Chem. Soc. November 2012, 89(11): 1951-1960, (2012).

4. J. Ochoa (coord.). Industria quimica basada en biomasa implicaciones tecnológicas. Informe. Final 2007. Fundación LEIA CDT por encargo de Observatorio Químico del MICYT (2007). 105 pag.

5. I. Homer, F. Ruiz, M. Sanchez, P. Calandra. VII Congreso Iberoamericano de Agroingeniería y Ciencias Hortícolas. Madrid, 26-29. Agosto 2013. (2013).

6. M. Vieira, M. da Silva, A. Maçumoto, L. Santos, M. Beppu. Mat. Res. Vol.17, n.2, pp. 386-391, (2014).

7. T. Saurabh, M. Patnaik, S. Bhagt, V. Renge. International Journal of Advanced Engineering Technology. Vol.II/Issue IV/October-December, 491-501, (2011). 
8. B. M. Abdullah, J. Salimon. J. Appl. Sci. 10(15):1545-1553, (2010).

9. M. Milchert, A. Smagowicz, G. Lewandowski. J Chem. Technol. Biotechnol. 85:1099-1107, (2010).

10. M-C. Kuo, T-C. Chou. Ind Eng Chem Res 26(2):277-284, (1987).

11. M. Rüsch gen. Klaas, S. Warwel. Ind. Crops Prod., 9, 125-132, (1999).

12. M. Guillen, N. Cabo. Food Chem. 77: 503-510, (2002).

13. D. Goburdhun, S. Jhaumeer-Laulloo, R. Musruck. Int. J. Food Sci. Nutr. 52 (1) $31-42,(2001)$

14. Y. Zhang, Y. Zhang, X. Chen, Y. Zhang. Reactive \& Functional Polymers 47. 93-99, (2001).
15. N. Vlachos, Y. Skopelitis, M. Psaroudaki, V. Konstantinidou, A. Chatzilazarou, E. Tegouet. Analytica Chimica Acta, 573-574: 459-465, (2006).

16. ICONTEC. NCT 2366. Aceites vegetales epoxidados de soya y linaza. 11 pag, (2000).

17. ICONTEC. NTC 3305. Plásticos. Muestreo y evaluación de los plastificantes utilizados en plásticos. 8 pag, (1997).

18. L. Boyacá, A. Beltrán. Ingeniería e Investigación 30(1):136-40, (2010).

19. J. Espinoza, D. Haagenson, S. Pryor, C. Ulven, D. Wiesenborn. Transactions of the ASABE. 52(4): 1289-1297, (2009) 